\title{
The Need for Graduate Orientation
}

\author{
by Melissa E. Lang \\ Graduate Assistant, Greek Life \\ University of Arkansas
}

Graduate students flock to university campuses each year in the search of obtaining a new level of education, with some looking for jobs, and some pursuing education for its own means. Student choose their institutions for different reasons; some sought to attend the "best" institution in their field, others wanted to receive a new experience in a different part of the country, some followed assistantships, and some students only had one option. To some extent, students are usually recruited, and assistance is provided to navigate the sometimes difficult application process and test taking. But what happens after the recruiting is over and students are accepted? Often, little is done, which is surprising, particularly for graduate preparation programs in higher education and student affairs. Are institutions so focused on orienting undergraduates that graduate 
students are forgotten?

Graduate students, much like their undergraduate counterparts, are about to embark on a new experience full of exciting opportunities and numerous challenges. An orientation process, with goals and objectives similar to the undergraduate experience, is essential in the retention and success of graduate students.

\section{Why Orient Anyone to a University?}

As described by Rentz (1996), "all programs should: (1) aid students in their academic adjustment; (2) provide assistance with personal adjustment; (3) help entering students' families understand the collegiate experience; and (4) assist the institution in gathering data about its entering students" (p. 244). The goals of orientation program planners should not be limited to the undergraduate experience. If it is viewed as important for some new university students, it should be viewed as important for all new university students. Students at all levels face adjustments when entering a new environment; and therefore, it is imperative that student affairs professionals meet the needs of all students. Rentz (1996) also noted that "Entering students report several fears they had about their entrance into a new educational community. Among them: their inability to do college work, to select the right major, to make friends, and to find a desirable roommate" (p. 247). These fears are the same for graduate students.

After entering graduate school, many students question their own abilities. The first time they write a paper, they fear that it is not up to "graduate" standards. Additionally, it can be difficult for graduate students to feel instantly comfortable in their classroom setting because of the age differences and backgrounds of their peers. Many graduate students find themselves, during class, questing their own comments, beliefs and thoughts among their classmates. The diversity of a classroom adds to the depth of learning, and often the graduate student is not prepared for this change. And, just as graduate students are more likely to initially doubt their ability to perform, they also begin to question their commitment to their discipline and the profession for which they are training. A strong orientation program for graduate students can be a powerful tool in reducing the fear and apprehension of new students, and has the potential to not only improve retention, but improve the overall educational experience.

Finally, the fear of not building social support structures (that is, making friends), can be a big part of a graduate student's life. Unlike undergraduates, they are not living in a residence hall and their classes, and class sizes, are limited and restricted. This can be extremely challenging for students that need social interaction, and can be compounded if graduate student relocates to a different part of the country. Adjusting to a new environment without the necessary support system can be strongest contributing factors to a graduate student's lack of success.

\section{Orientation for Graduate Students}

Many universities do provide some form of graduate orientation, but these programs 
are typically abbreviated experiences that last several hours to a day at most. If a one-day orientation process is not enough for undergraduates, on what basis is it considered adequate for graduate students? The coordination efforts for these programs are often housed in graduate schools or in academic departments, and strangely, offices of new student orientation that coordinate undergraduate programs do not take control or assist with them. Yet, the goals for graduate student orientation, much like those for undergraduates, are strikingly similar: helping students adjust academically and personally, aiding families in the adjustment, and providing the tools to be successful in and out of the classroom.

Universities should be the catalyst for providing assistance to all graduate students. Academic and personal adjustments could be tackled through a graduate orientation office that focuses on the needs of all graduate students, not just a particular department. If programs were developed that aided graduate students in feeling comfortable about their academic transition, then universities may experience greater academic quality from students, in addition to the student gaining a sense of university belonging.

Additionally, the purpose of most orientation programs is to help students form a connection with the university, a connection that will ultimately be life-long. In providing graduate orientation, the institution will help the student make their connection and feel bonded.

Just as orientation at an undergraduate level is imperative for future success, graduate orientation is necessary to enhance the learning. In order to fulfill institutional missions and create graduates that will represent the university community positively, student affairs professionals must reevaluate the needs of graduate students and begin developing programs to meet those needs. The establishment of an extensive graduate orientation process should be the first step in meeting those needs.

\section{References}

Rentz, A. L. (1996). Student affairs practice in higher education, (2nd edition). Springfield, IL: Charles C. Thomas. 